\title{
Rejection Monitoring by Lymphocyte Blastogenesis Assay in Canine Lung Allotransplantation
}

\author{
Shigefumi Fujimura, Takashi Kondo, Atsushi \\ Yamauchi, Takeshi Okabe, Masashi Handa, Fumihiro \\ Shionozaki, Ryo SaIto, Masahiro Horikawa* and \\ TASUKU NAKADa \\ Departments of Surgery and *Pediatrics, the Research \\ Institute for Tuberculosis and Cancer, Tohoku University, \\ Sendai 980
}

Fujimura, S., Kondo, T., Yamauchi, A., Okabe, T., Handa, M., Shionozaki, F., Saito, R., Horikawa, M. and Nakada, T. Rejection Monitoring by Lymphocyte Blastogenesis Assay in Canine Lung Allotransplantation. Tohoku J. exp. Med., 1984, 142 (3), 321-335 — Seventy-seven adult mongrel dogs underwent left lung transplantation to study the immunological detection of posttransplant rejection response using the lymphocyte blastogenesis assay. Experimental animals were divied into 3 groups; control autotransplantation (4 dogs), control allotransplantation (32 dogs) and immunosuppressed allotransplantation (41 dogs). The lymphocyte blastogenesis assay included mixed lymphocyte reaction (MLR), lymphocyte reactivity to lectins (PHA, ConA and PWM) and spontaneous blastogenesis in peripheral lymphocyte culture methods. The latter two tests were performed in serial blood samples up to the 38th posttransplant day. In the control autotransplant group there were no particular changes in posttransplant PHA reactivities. In the animals with lung allograft, results of preoperative MLR between donor and recipient showed no particular relationships to posttransplant rejection response. The recipient, however, showed a decreased response to PHA and an increased spontaneous blastogenesis at the period undergoing rejection which were confirmed by blood samples taken within 2 days before sacrifice of animals whose transplant specimens showed apparent histologic findings of rejection. In the immunosuppressed allotransplantation group, those findings of PHA response and spontaneous blastogenesis had often preceded the rejection episode detected on chest $\mathrm{x}$-ray films, whereas there were no particular changes in both parameters of dogs bearing enhanced allografts. The serial detection of spontaneous blastogenesis and PHA reactivity in peripheral lymphocyte may be one of the useful methods for early prediction of rejection episode in lung transplantation. lung transplantation; rejection monitoring; spontaneous blastogenesis ; PHA blastogenesis

The number of patients who need lung transplantation goes on increasing year by year. The situation of a clinical application of this method, however, is 
still difficult compared to the transplantation of other organs (Veith 1978). The success of lung allotransplantation depends on the preservation of suitable donor lungs and on the control of rejection. The onset of rejection in the allotransplanted lung causes not only deterioration in alveolar-capillary function of the lung, which is frequently associated with infection, but also disruption or granulation around the bronchial anastomotic site on account of decreased circulation in the bronchial artery. Rejection phenomenon in the allotransplant is often irreversible even when it is diagnosed by clinical examinations including chest $\mathrm{x}$-ray films. Early prediction of an onset of rejection is particularly important in the lung transplantation. In this connection, the early detection of immunological signs is regarded as the most effective (Fujimura et al. 1977a, b, 1978a, b, 1979).

In this paper, attempts were made to evaluate whether the results of serial non-specific lymphocyte blastogenesis tests including response to lectins and spontaneous blastogenesis can contribute to an early prediction of the rejection episode in canine lung allotransplantation.

\section{Materials and Methods}

Seventy-seven adult mongrel dogs underwent left lung transplantation. They were divided into 3 groups; (I) control autotransplants (4 dogs), (II) control allotransplants (32 dogs) and (III) immunosuppressed allotransplants (41 dogs) (Table 1).

Mixed lymphocyte reaction (MLR) between donor and recipient was preoperatively carried out in 17 allotransplantations. As postoperative immunological parameters of the recipients, lymphocyte blastogenesis to lectins including phytohemagglutinin (PHA), concanavslin A (Con-A) and pokeweed mitogen (PWM), and lymphocyte spontaneous blastogenesis (SB) were tested in serial peripheral blood using a culture method of small whole blood sample up to the 38 th postoperative day. In addition to these immunological examinations, serial postoperative chest $\mathrm{x}$-ray films and histologic views of the transplanted lung revealed at the autopsy were studied in relation to the rejection phenomena of the lung allotransplants.

\section{Lung transplantation}

All experiments were performed on 77 mongrel dogs weighing 9 to $21 \mathrm{~kg}$ which were anesthetized by intravenous injection with 20 to $25 \mathrm{mg} / \mathrm{kg}$ of sodium pentobarbital. They were intubated and underwent autotransplantation or allotransplantation of the left lung.

TABLE 1. Experimental group and lmphocyte blastogenesis in lung transplantation

\begin{tabular}{|c|c|c|c|c|c|c|c|c|}
\hline & & \multirow{2}{*}{$\begin{array}{c}\text { Number } \\
\text { of } \\
\operatorname{dogs}\end{array}$} & \multirow{2}{*}{$\begin{array}{l}\text { Postop. } \\
\text { day of } \\
\text { sampling }\end{array}$} & \multicolumn{5}{|c|}{ Lymphocyte blastogenesis } \\
\hline & & & & MLR & PHA & ConA & PWM & SB \\
\hline I. & $\begin{array}{l}\text { Control } \\
\quad \text { autotransplants }\end{array}$ & 4 & $0-7$ & - & 4 & - & - & - \\
\hline II. & $\begin{array}{l}\text { Control } \\
\quad \text { allotransplants }\end{array}$ & 32 & $0-11$ & 1 & 29 & 7 & 13 & 4 \\
\hline III. & $\begin{array}{l}\text { Immunosuppressed } \\
\text { allotransplants }\end{array}$ & 41 & $0-38$ & 16 & 40 & 11 & 11 & 20 \\
\hline
\end{tabular}

MLR, mixed lymphocyte reaction; SB, spontaneous blastogenesis. 
Techniques of lung transplantation have been described previously (Suzuki et al. 1968; Fujimura et al. 1972). The group of lung autotransplantation consisted of 4 animals. 73 dogs with lung allotransplantation included 32 control allotransplants and 41 immunosuppressed allotransplants. In 10 animals out of the latter 41, the excised lungs from the heparinized donor were perfused with electrolyte solution at a flow rate of $1 \mathrm{ml} / \mathrm{kg} / \mathrm{min}$ for $6 \mathrm{hr}$ under 3 to $5^{\circ} \mathrm{C}$ temperature, and were transplanted (Kondo et al. 1980). In 63 animals with lung allotransplantation, the left lung was excised from the heparinized donor and immediately transplanted to the recipient. The anastomoses of pulmonary veins and arteries were completed with continuous suture techniques using 4-0 Tefdek. The bronchus was reconstructed with 3-0 Dexon. Time used in the transplantation techniques was less than $1 \mathrm{hr}$. Postoperatively, antibiotics including carbenicillin, cephalosporins and aminoglucosides were daily adminstered to all animals.

\section{Immunosuppressive treatment}

As postoperative immunosuppression, 50 to $100 \mathrm{mg}$ of azathioprine were administered with 1 to $4 \mathrm{mg}$ of dexamethazone or betamethazone to 31 animals in which the immediate transplantation was carried out. To $10 \mathrm{dogs}$ with a preserved lung transplanted, $100 \mathrm{mg}$ of azathioprine were administered every day from the second day after the operation to one week. After that week period, the drug was decreased to $50 \mathrm{mg}$ for the next one week. Thereafter the drug was reduced to $25 \mathrm{mg}$ after another week. In this group $250 \mathrm{mg}$ of methylprednisolone were injected on the day of experiment, $100 \mathrm{mg}$ from the following day, and $50 \mathrm{mg}$ from the second week after the operation.

\section{Lymphocyte blastogenesis}

Mixed lymphocyte reaction (MLR). Heparinized blood samples were obtained from the the donor and the recipient preoperatively. After removal of plasma from $2 \mathrm{ml}$ of the donor sample, the same volume of Hungerford's culture medium as that of removed plasma, and $100 \mu \mathrm{g}$ of mitomycin $\mathrm{C}$ were added and incubated for $30 \mathrm{~min}$ at $37^{\circ} \mathrm{C}$. This sample was prepared as stimulator cells after centrifuging and washing it 3 times. $0.2 \mathrm{ml}$ of the recipient blood and $0.2 \mathrm{ml}$ of the stimulator sample were both placed in a culture tube and incubated for 6 days in a $\mathrm{CO}_{2}$ incubator. Another incubation of this sample was performed without stimulator cells. $2.5 \mu \mathrm{Ci}$ of ${ }^{3} \mathrm{H}$-thymidine, and $10 \mu \mathrm{g}$ of cold thymidine were added to each tube $24 \mathrm{hr}$ before harvesting. After the harvesting, the samples were transferred to scintillation vials, and the radioactivity was measured in a liquid scintillation counter.

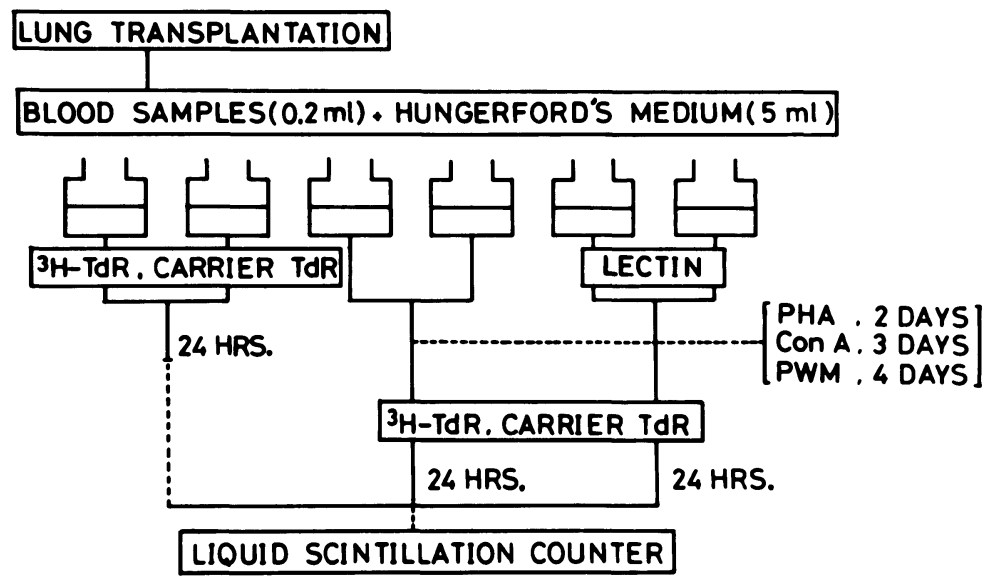

Fig. 1. Experimental protocol of the examination of spontaneous blastogenesis and response to lectins of peripheral lymphocytes in lung allotransplantation. 
The ${ }^{3} \mathrm{H}$-thymidine incorporation was recorded as dpm per $10^{6}$ lymphocytes. Stimulation index (SI) was calculated by the following formula; $\mathrm{SI}=\mathrm{dpm}$ with stimulator cells/ without stimulator cells.

Lymphocyte blastogenesis to lectins and spontaneous blastogenesis (SB). Experimental protocol is summarized in Fig. 1. Serial peripheral blood samples were taken and cultured pre- and postoperatively to study the lymphocyte blastogenesis to lectins including PHA, Con-A and PWM, and lymphocyte spontaneous blastogenesis. $0.2 \mathrm{ml}$ of heparinized blood excluded plasma plus $5 \mathrm{ml}$ of Hungerford's medium were cultured for $24 \mathrm{hr}$ in a $\mathrm{CO}_{2}$ incubator. The ${ }^{3} \mathrm{H}$-thymidine incorporation of this culture range was fixed as spontaneous blastogenesis. For lymphocyte blastogenesis to lectins such as $\mathrm{PHA}$, Con-A and PWM, ${ }^{3} \mathrm{H}-$ thymidine uptake was measured after 3,4 and 5 days of incubation respectively. ${ }^{3} \mathrm{H}-$ thymidine and carrier thymidine were added $24 \mathrm{hr}$ before the harvesting. Stimulation index (SI) was calculated by the following formula; SI=dpm with lectins/dpm without lectins.

\section{Other examinations}

Chest $\mathrm{x}$-ray films were taken more than two times a week after the operation. The histologic examinations were carried out in lung specimens obtained from the recipient immediately after death or sacrifice in which the dogs were put to death following intravenous injection of a high dose of sodium pentobarbital and heparin. Lung specimens were fixed in $10 \%$ neutral formalin and sections were stained with hematoxylin and eosin.

\section{Results}

Preoperative lymphocyte blastogenesis

The results of the preoperative lymphocyte blastogenesis are summarized in Table 2. MLR undertaken in 17 recipients with lung allotransplantation varied from 0.8 to 2.7 and the mean value was 1.5 , when they were expressed as stimulation index (SI). When the results of lymphocyte blastogenesis to lectins were

TABle 2. Preoperative lymphocyte function in lung transplantation

\begin{tabular}{cllcc}
\hline \multicolumn{2}{c}{ Lymphocyte culture } & Mean values & Range \\
\hline MLR & Control & $\left(\mathrm{dpm} / 10^{6}\right.$ cells $)$ & 806 & $140-3,601$ \\
$(17)$ & MLR & $\left(\mathrm{dpm} / 10^{6}\right.$ cells $)$ & 1,021 & $290-3,687$ \\
& SI & 1.5 & $0.8-2.7$ \\
PHA & Control & $\left(\mathrm{dpm} / 10^{6}\right.$ cells $)$ & 890 & $41-11,444$ \\
$(73)$ & With PHA & $\left(\mathrm{dpm} / 10^{6}\right.$ cells $)$ & 6,046 & $329-48,945$ \\
& SI & & 12.6 & $0.7-69.1$ \\
ConA & Control & $\left(\mathrm{dpm} / 10^{6}\right.$ cells $)$ & 1,219 & $209-3,806$ \\
$(18)$ & With ConA & $\left(\mathrm{dpm} / 10^{6}\right.$ cells $)$ & 16,133 & $1,618-129,401$ \\
& SI & & 15.6 & $2.3-80.8$ \\
PWM & Control & $\left(\mathrm{dpm} / 10^{6}\right.$ cells $)$ & 1,482 & $144-5,389$ \\
$(24)$ & With PWM & $\left(\mathrm{dpm} / 10^{6}\right.$ cells $)$ & 15,050 & $227-120,194$ \\
& SI & & 15.6 & $0.7-94.8$ \\
Spontan & & 1,651 & $361-6,068$ \\
$(24)$ & & $\left(\mathrm{dpm} / 10^{6}\right.$ cells $)$ & & \\
\hline
\end{tabular}

( ), number of dogs; SI, stimulation index $=$ control/with mitogen. 
expressed as SI, they were 0.7-69.1 to PHA, 2.3-80.8 to Con-A and 0.7-94.8 to PWM, and the mean values were 12.6, 15.6 and 15.6 respectively. Preoperative spontaneous blastogenesis was detected in 24 allotransplanted animals, and the result varied from 361 to $6,068 \mathrm{dpm}$ with a mean value of $1,651 \mathrm{dpm}$.

\section{Lymphocyte function in lung autotransplantation}

In 4 animals with lung autotransplantation, PHA response was examined as peripheral lymphocyte function. These dogs showed no specific tendencies in postoperative PHA blastogenesis, though the period examined was up to 7 days postoperatively (Fig. 2).

\section{Postoperative lymphocyte blastogenesis in control allotransplantation}

Lymphocyte blastogenesis was studied in 32 animals with control lung allografting up to 11 days after the operation. The values of preoperative SI varied from those of high response to those of low reactions to lectins. However, in those whose preoperative SI values were more than 10 , the postoperative values tended to decrease once early after the operation and to increase thereafter; while
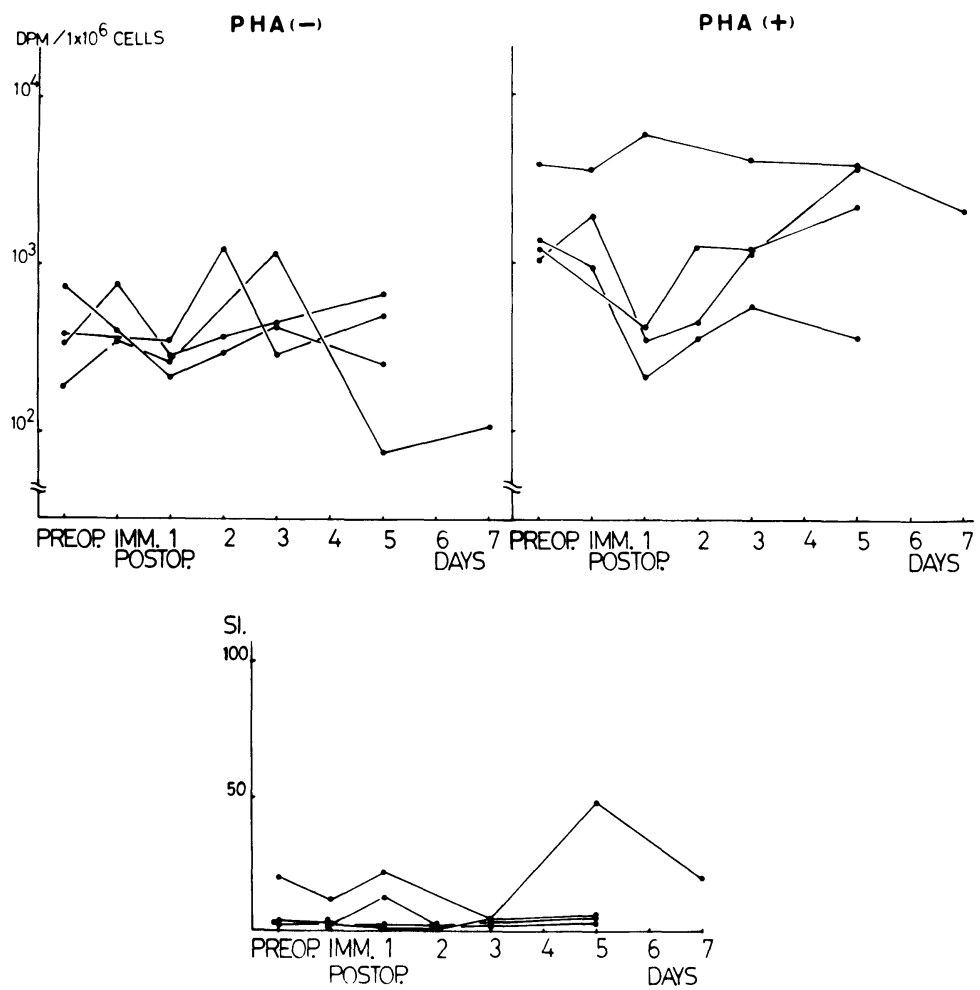

Fig. 2. The time course of ${ }^{3} \mathrm{H}$-thymidine incorporation in serial blood samples of autotransplanted dogs. Note that they show no specific tendency in PHA response of peripheral lymphocytes postoperatively.

$\mathrm{SI}$, stimulation index $=\mathrm{dpm}$ in $\mathrm{PHA}(-) / \mathrm{dpm}$ in $\mathrm{PHA}(+)$. 
in the animals whose preoperative SI values were less than 10, the postoperative values showed little changes. These results described above have been reported elsewhere (Fujimura et al. 1977b, 1978b, 1979).

In order to study the relationship between lymphocyte blastogenesis and rejection response in control allotransplantation, attempts were made to compare the histologic findings of the lung which showed undergoing rejection, with results of lymphocyte blastogenesis (Fig. 3). In this study, the animals whose transplanted lungs revealed such histologic features as completion of rejection and/or

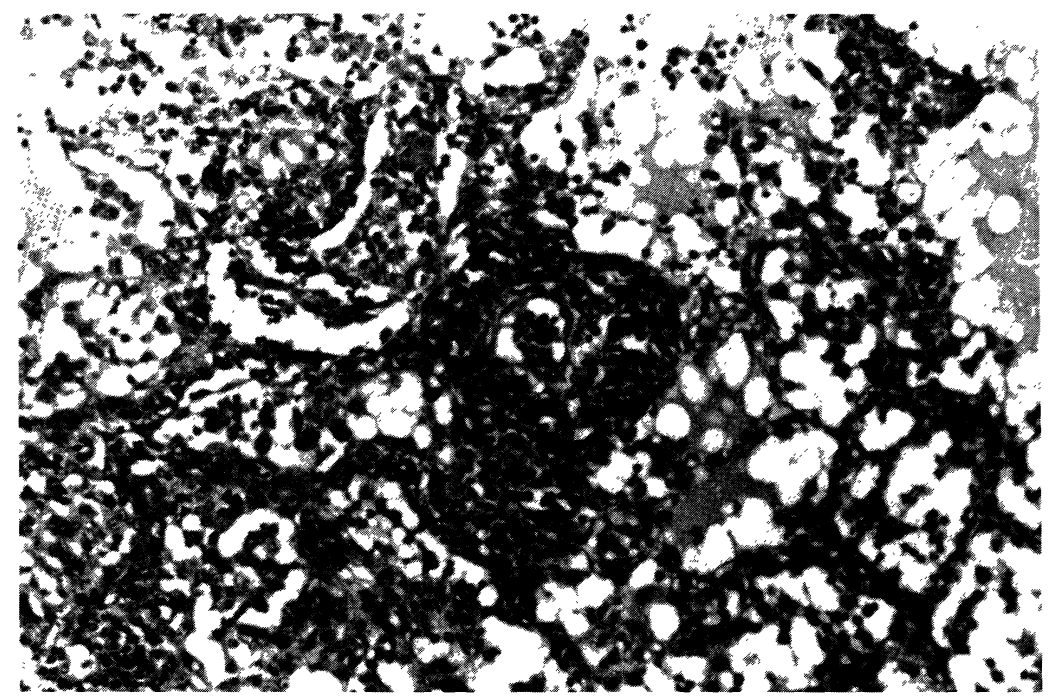

Fig. 3. The histologic appearance of the lung allotransplant.

Perivascular collection of lymphocytes and inflammatory cell infiltration in alveoli are seen. These findings indicate that rejection is undergoing in the lung transplant $(\mathrm{HE}, \times 80)$.

apparent infection were excluded. In those animals whose transplanted lungs showed apparent progressive rejection, SI of PHA reactivity of the sample obtained within 2 days from the time of sacrifice showed significantly lower levels $(p<0.05)$, and spontaneous blastogenesis of the same sample demonstrated significantly increased levels $(p<0.05)$, when compared with those of the preoperative blood samples (Fig. 4).

\section{Postoperative lymphocyte blastogenesis in immunosuppressed allotransplantation}

Lymphocyte blastogenesis was examined in 41 dogs with immunosppressed lung allotransplants up to the 38th day after the operation. There were no specific relationships between preoperative MLR values and postoperative lymphocyte functions or histologic findings of the transplanted lungs. Serial postoperative lymphocyte blastogenesis to lectins were apt to be decreased in early postoperative period. 


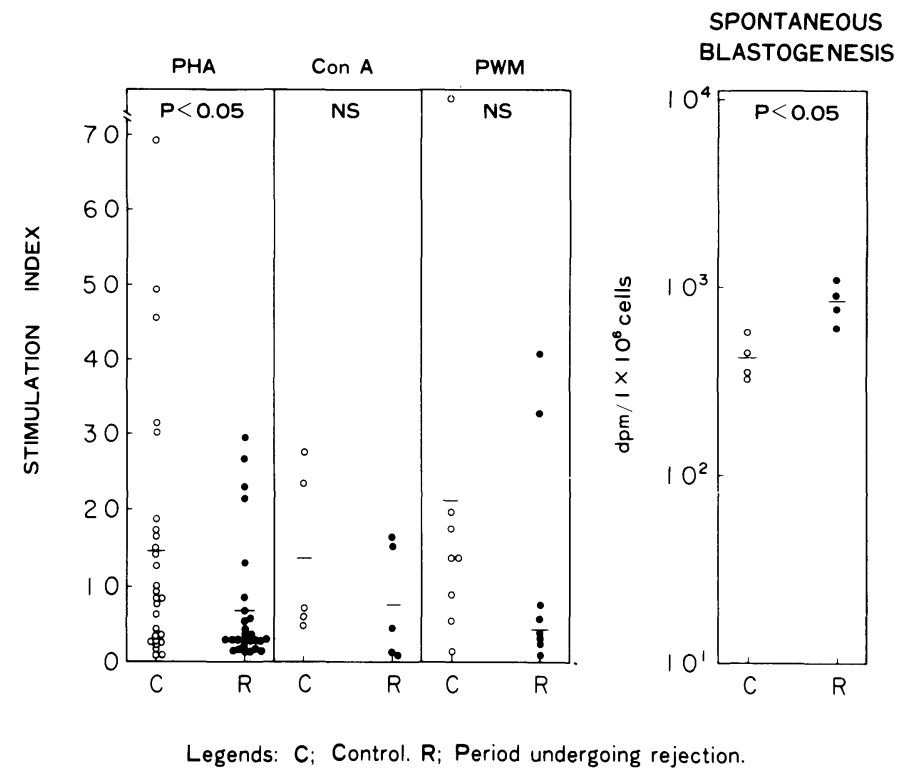

Fig. 4. Changes in peripheral lymphocyte functions at the period undergoing rejection in control lung allotransplants. Note significant changes in PHA reactivity and spontaneous blastogenesis at the period.

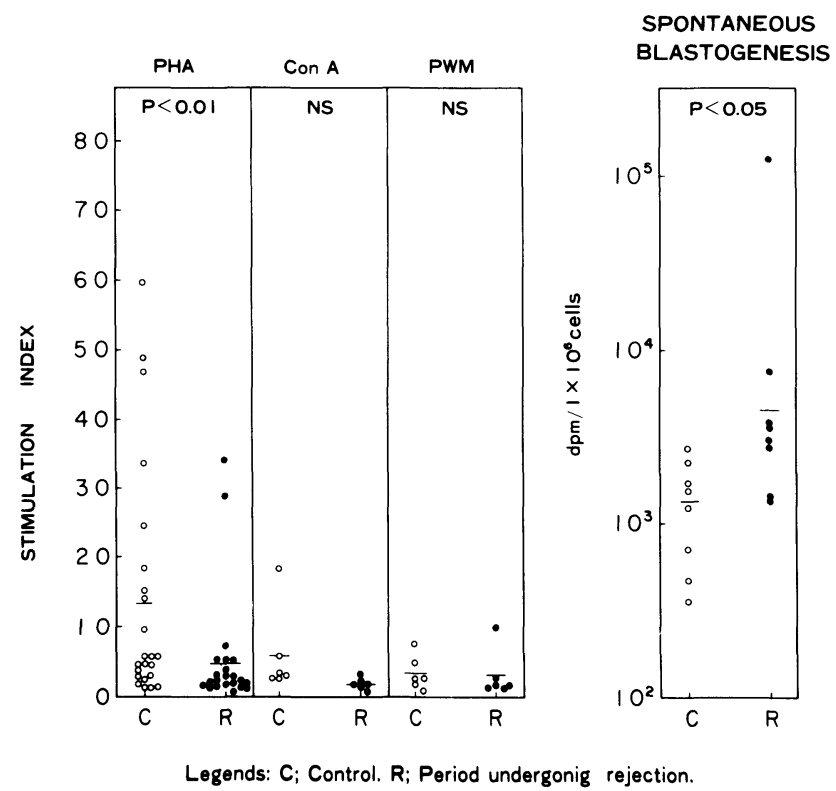

Fig. 5. Changes in peripheral lymphocyte functions at the period undergoing rejection in immunosuppressed lung allotransplants.

Note significant changes in PHA reactivity and spontaneous blastogenesis at the period. 
Peripheral blood samples were taken from the recipients 2 days before the autopsy and from 11 to 40 days after the operation. These results of lymphocyte blastogenesis were compared to those obtained preoperatively. There were similar tendencies to the results of control allotransplantation in the immunosuppressed animals whose transplanted lungs revealed undergoing rejection histologically ; lymphocyte blastogenesis to lectins showed a lowering tendency, especially in PHA response $(p<0.01)$, and spontaneous blastogenesis was increased $(p<0.05)$ (Fig. 5).

Neither postoperative spontaneous blastogenesis nor SI of PHA reactivity showed any significant tendency in the animals where there were no changes in the serial postoperative chest $x$-ray findings nor histologic finding of rejection in the transplant obtained at the time of sacrifice (Figs. 6, 7). However, there were some obvious changes in spontaneous blastogenesis and SI of $\mathrm{PHA}$ reactivity not infrequently in the cases which showed a certain infiltrative shadow on the left side of chest $\mathrm{x}$-ray films (Figs. 8, 9). These changes in the postoperative lymphocyte blastogenesis tended to precede the changes shown in chest $\mathrm{x}$-ray findings

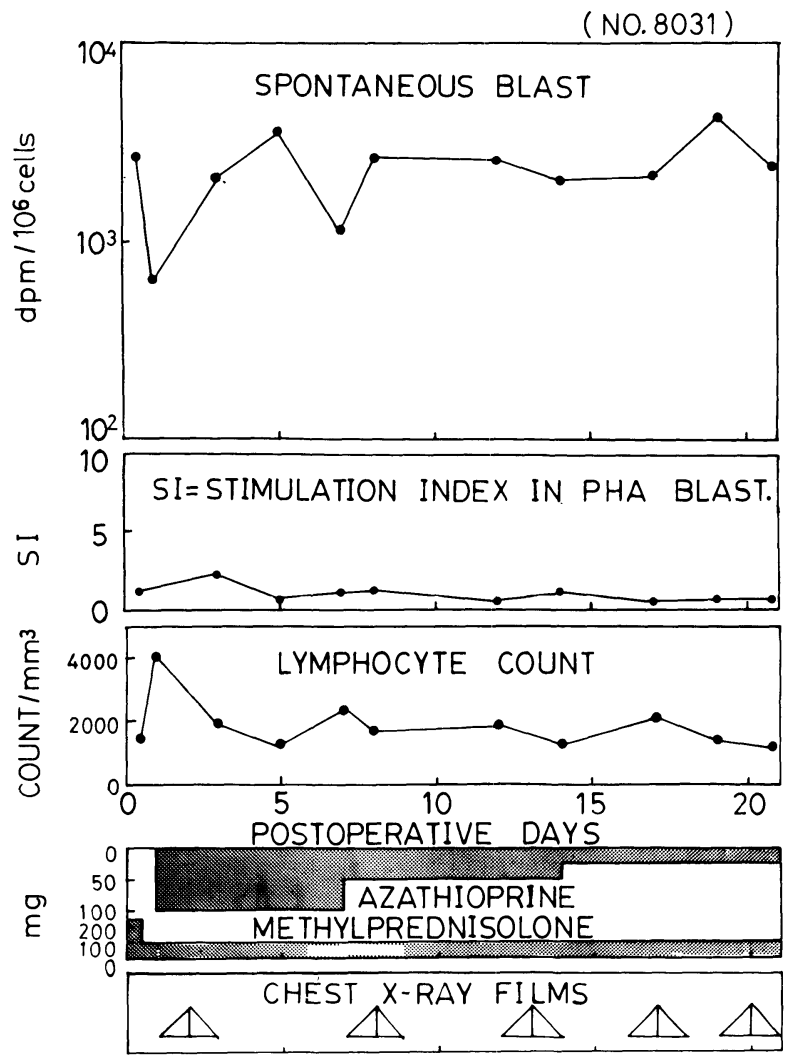

Fig. 6. The time course of changes in lymphocyte functions and chest $x$-ray findings in an immunosuppressed lung transplant (No. 8031). There are no particular changes in those functions or in chest $\mathrm{x}$-ray findings. 


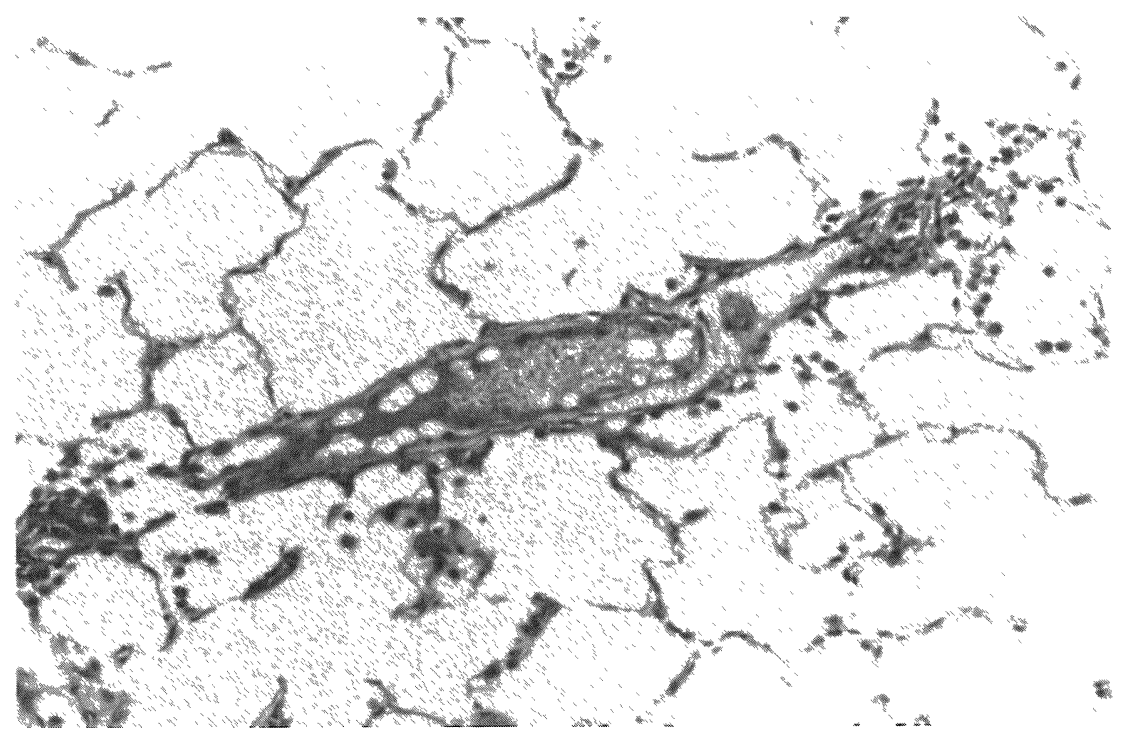

Fig. 7. The histologic appearance of the transplanted lung of No. 8031. The lung shows normal histologic findings $(\mathrm{HE} . \times 80)$.

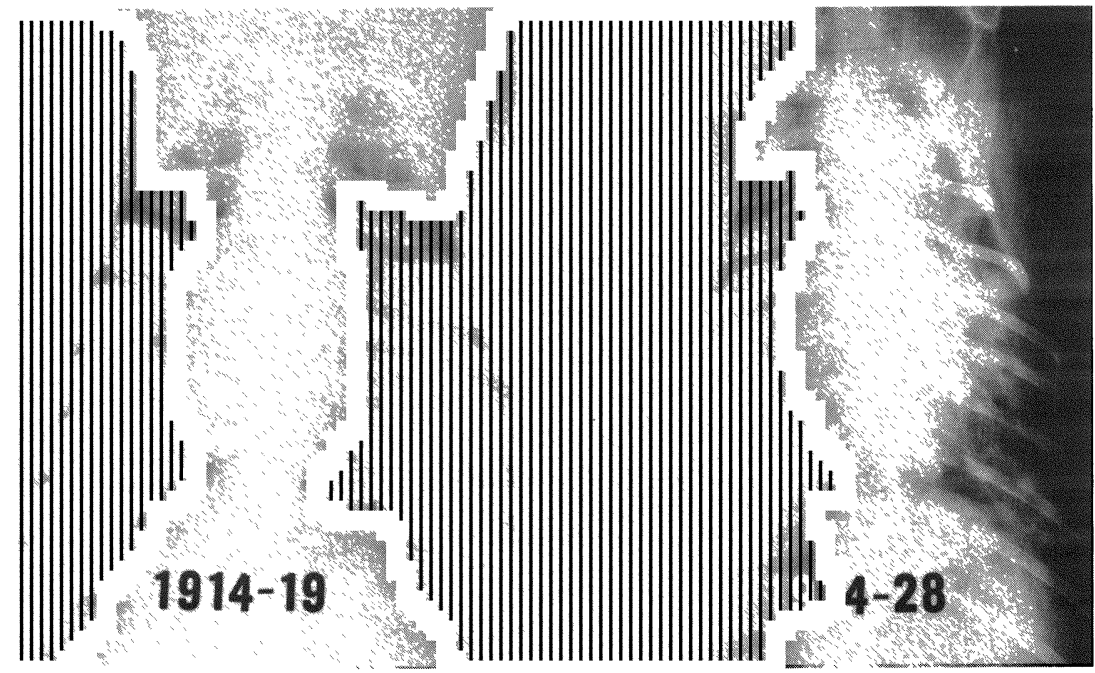

Fig. 8. Postoperative chest $\mathrm{x}$-ray films of an immunosuppressed lung allotransplant (No. 1914). On the 19th postoperative day the transplanted lung was normal. Infiltration appeared on the 28th day after the operation.

(Figs. 10, 11). These animals were sacrificed and a histologic examination of the transplanted lung showed that the rejection was undergoing at that period (Figs. $12,13)$. 

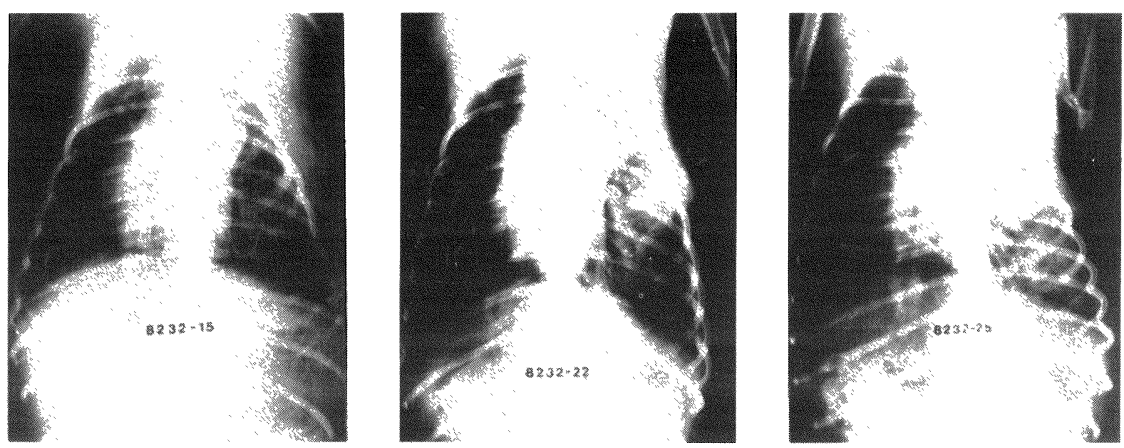

Fig. 9. Postoperative chest $\mathrm{x}$-ray films of a immunosuppressed lung allotransplant (No. 8232). On the 15th postoperative day the transplanted lung was normal. Infiltration appeared on the 22 th day and increased on the 25 th day after the operation.

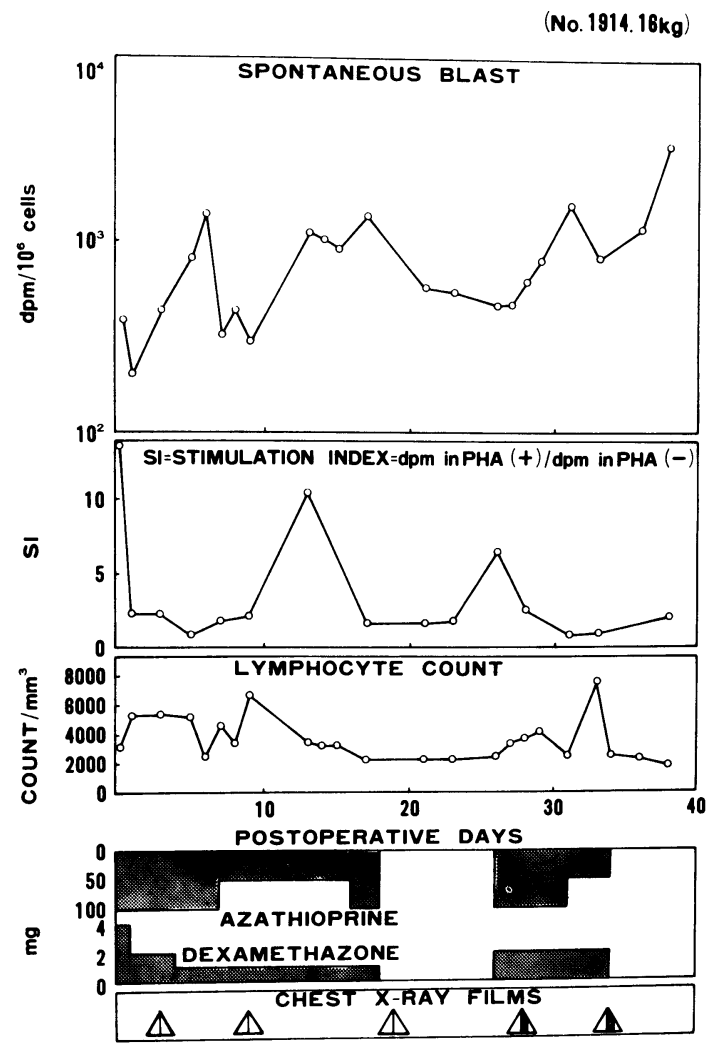

Fig. 10. The time course of changes in lymphocyte functions and chest $\mathrm{x}$-ray findings in No. 1914. Spontaneous blastogenesis of peripheral lymphocyte increased from 27 th day postoperatively. 

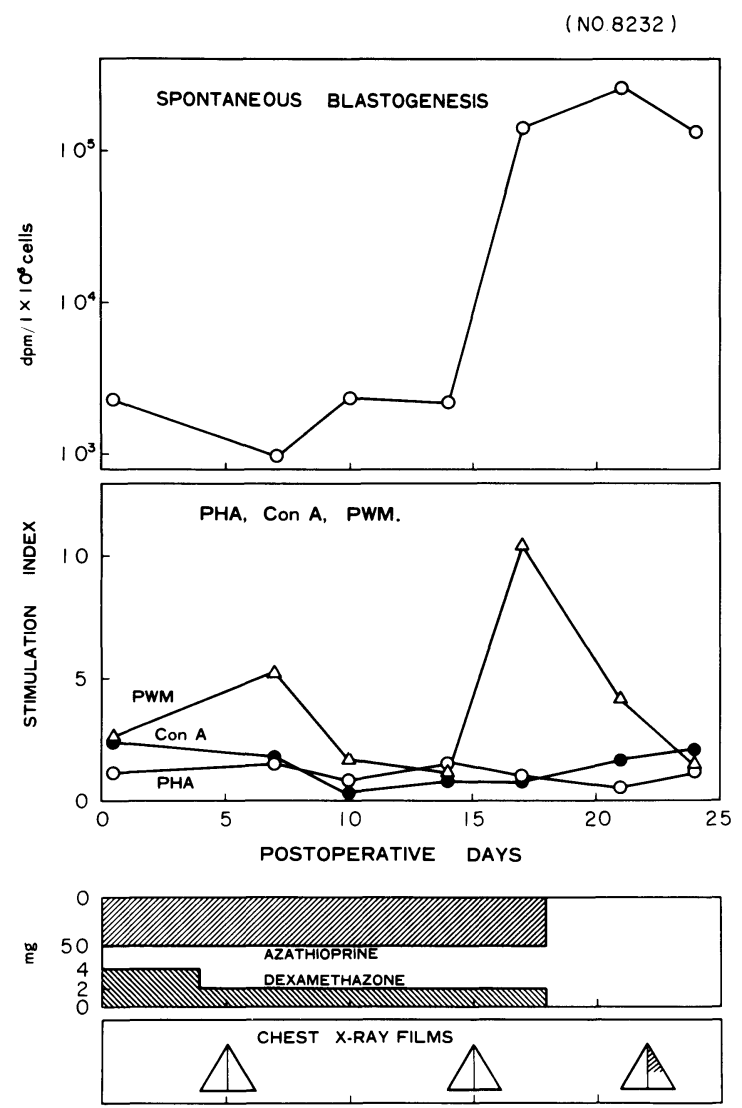

Fig. 11. The time course of changes in lymphocyte functions and chest $\mathrm{x}$-ray findings in No. 8232. Spontaneous blastogenesis of peripheral lymphocyte remarkably increased from the 17 th day postoperatively.

\section{Discussion}

Histologically, the acute rejection of the transplanted lung is proved by the infiltration of mononuclear cells mainly composed of lymphoid cells fround interstitial area of the lung, and by the effusion including inflammatory cells to the alveoli. Those progresses cause a severe destruction of the pulmonary structures. The affected lung is apt to be infectious because of its anatomical characteristics.

Veith and his colleagus (Veith et al. 1973) reported that the diagnosis of the lung transplant rejection episode is feasible when there are fewer, decrease in arterial $\mathrm{PO}_{2}$, leukocytosis and the occurrence of infiltration on chest $\mathrm{x}$-ray film without any changes in bacterial agents daily examined in sputum. Recently they also performed and evaluated an analysis of bronchoalveolar lavage fluid via a feberoptic bronchoscope for a probe of acute allograft rejection of lung transplant (Veith et al. 1981). More recently, Reize et al. (1983) reported successful 


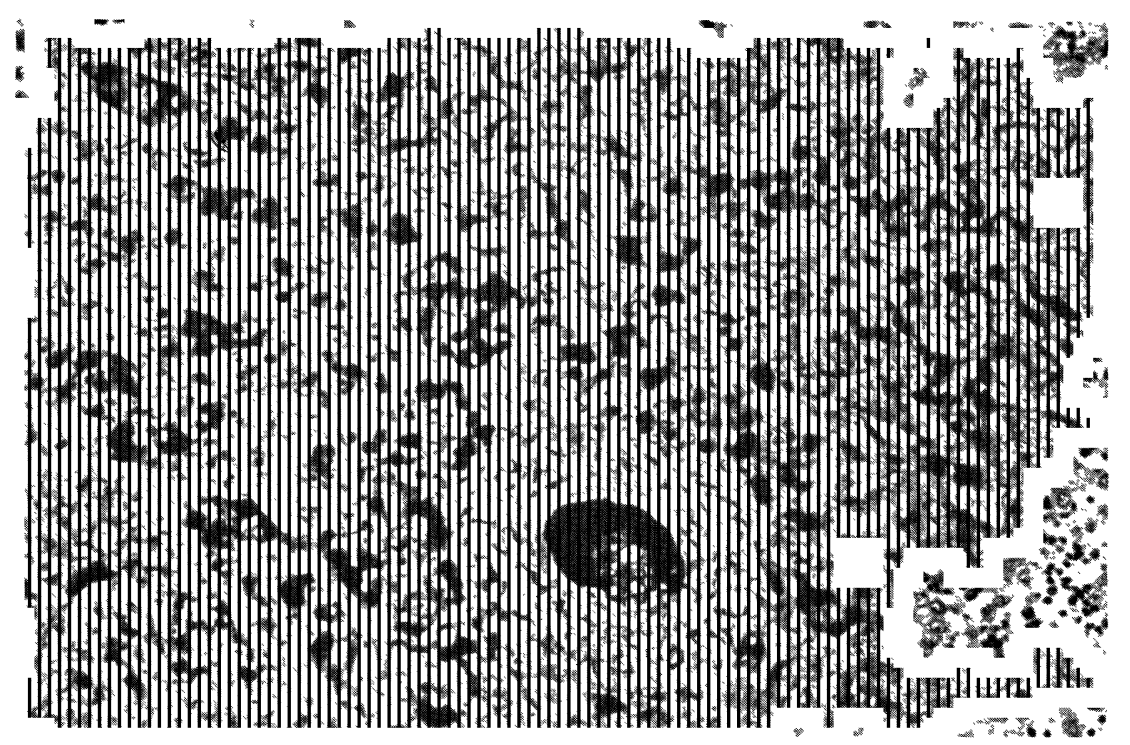

Fig. 12. The histologic appearance of the lung transplant at 40 days after the grafting (No. 1914), showing rejection $(\mathrm{HE}, \times 80)$.

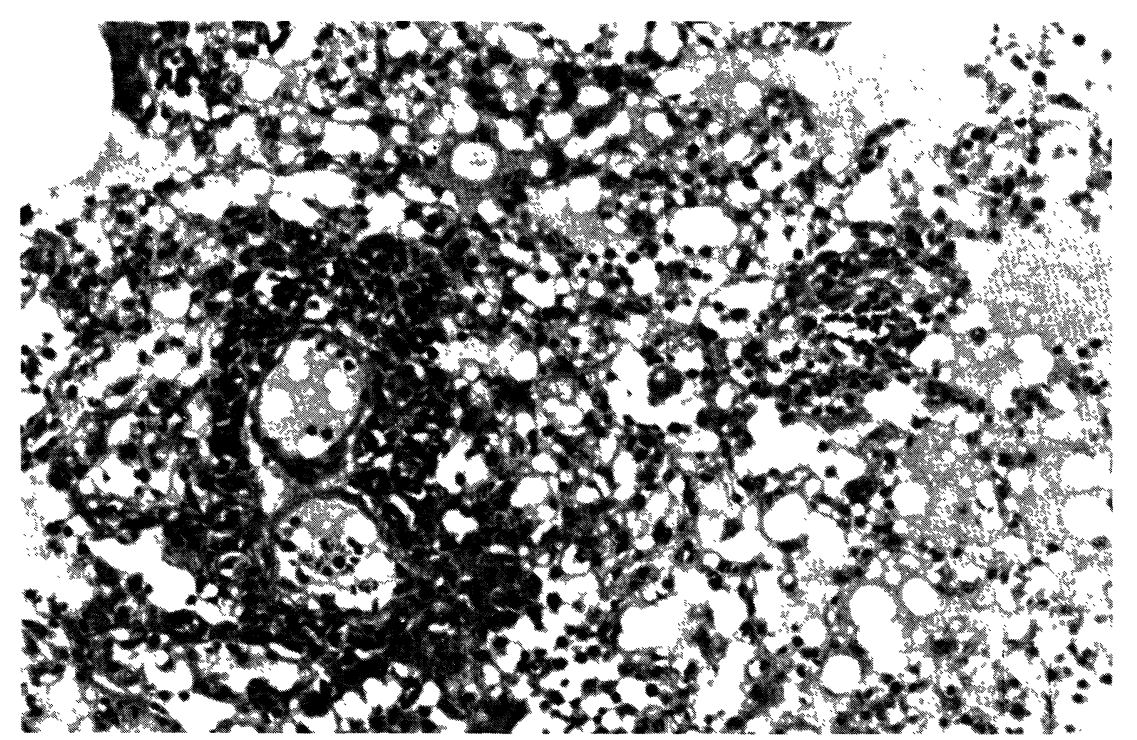

Fig. 13. The histologic appearance of the lung transplant at the 25 th day postoperatively (No. 8232), showing rejection $(\mathrm{HE}, \times 80)$.

cases of clinical heart-lung allotransplantation in which they applied CyclosporinA as an immunosuppressive agent and they evaluated a transvenous endomyocardial biopsy as an effective method for diagnosis of rejection. However, up to date it seems that there have been no specific and reliable methods available to assess rejection episodes after lung allotransplantation. One of the most impor- 
tant factors for an effective treatment of allograft rejection is early diagnosis of the onset of rejection, and this is especially true in lung transplantation.

According to our series of studies on rejection in lung transplantation (Fujimura et al. 1970, 1973, 1977a, b, 1978a, b, 1979), we reached the conclusion that the serial immunological examination of the peripheral lymphocyte after the operation may be useful to predict the onset of rejection even when the transplanted animals are under immunosuppressive treatment.

Immunological observations of rejection in organ transplantation have been making progresses mainly in renal transplants. Many of those measurements are depending on monitoring the quantitative and/or qualitative determinations of postoperative T lymphocyte (Kahan et al. 1979). Furthermore, there have been two ways for detecting allotransplant rejection; in one method of non-specific measurement, an increase in spontaneous blastogenesis as well as a decrease in active T-rosette forming cells has been once evaluated in early diagnostic procedures in renal transplantation (Kahan et al. 1979), while in another with use of donor target cells, lymphocyte mediated cytotoxicity (LMC) and complementdependent cytotoxicity (CDC) have been considered effective for rejection monitoring to date severally (Stiller et al. 1978; Kovithavongs et al. 1978).

In the lung allotransplantation a chance of concomitant infection is apt to exist at the rejection period, therefore, in our experiments the animals were sacrificed and histologic specimens confirmed dominant rejection findings.

Preoperative lymphocyte blastogenesis was compared with the blastogenesis within 2 days before death. Significant changes in spontaneous blastogenesis and SI of PHA response were found at the time of rejection. However, as it took at least 3 days to complete PHA reaction, actually spontaneous blastogenesis of lymphocyte can only be available for rejection monitoring.

Non-specific lymphocyte function in peripheral blood may be modified by such parameters as histocompatibility between donor and recipient, immunological capacity of recipient, immunosuppressive treatment, and entity of possible infection. Therefore, a single lymphocyte blastogenesis assay cannot necessarily show an onset of rejection. There were, however, many cases of our series of experiment that demonstrated an increase in spontaneous blastogenesis before showing an infiltrative shadow on chest $\mathrm{x}$-ray films. Additionally, there were also the cases whose spontaneous blastogenesis was kept decreased postoperatively as compared to that of the preoperative period, in which there were no changes in chest $\mathrm{x}$-ray findings during entire postoperative period.

Although spontaneous blastogenesis as a non-specific lymphocyte function has some false positive or false negative results, we are obliged to reach the conclusion that this blastogenesis assay can occupy one of the useful parameters predictable for an onset of rejection so far as it is applied with both PHA reactivity and serial chest $\mathrm{x}$-ray films. However, as combination of infection frequently occurs in a lung transplant, it is quite necessary to develop a specific 
lymphocyte function test for early prediction of rejection phenomena in lung allotransplantation.

\section{References}

1) Fujimura, S., Nakada, T., Kawakami, M., Sukeno, T., Yonechi, M., Okaniwa, G., Kagami, Y. \& Suzuki, C. (1970) Detection of immunoglobulins $(\gamma \mathrm{M}$ and $\gamma \mathrm{G})$ by fluorescent antibody method in canine lung allotransplantation. Tohoku $J$. exp. Med., 101, 183-198.

2) Fujimura, S., Parmley, W.W., Tomoda, H., Norman, J.R. \& Matloff, J.M. (1972) Hemodynamic alterations after staged and simultaneous bilateral lung autotransplantation in dogs. Immediate studies. $J$. thorac. cardiovasc. Surg., 63, 527-533.

3) Fujimura, S., Rosen, V., Adomian, G.E., Parmley, W.W., Suzuki, C. \& Matloff, J.M. (1973) Cellular characteristics of rejection response to canine lung allotransplants. $J$. thorac. cardiovasc. Surg., 65, 438-447.

4) Fujimura, S., Kondo, T., Sohara, Y., Okaniwa, G., Sukeno, T., Kawakami, M., Nakada, T. \& Horikawa, M. (1977a) Lung transplantation and lymphocyte function in dogs. I. Lymphocyte stimulation by mitogens. Jap. J. Transpl., 12, 188-192.

5) Fujimura, S., Kondo, T., Sohara, Y., Okaniwa, G., Sukeno, T., Kuwakami, M., Nakada, T. \& Horikawa, M. (1977b) Lung transplantation and lymphocyte function in dogs. II. Lymphocyte function in non-immunosuppressed animals. Jap. J. Transpl., 12, 193-200.

6) Fujimura, S., Kondo, T., Sohara, Y., Yamauchi, A., Kawakami, M., Nakada, T. \& Horikawa, M. (1978a) Lung transplantation and lymphocyte function in dogs. III. Correlation between lymphocyte function and histologic findings of the transplant. Jap. J. Transpl., 13, 190-194.

7) Fujimura, S., Kondo, T., Sohara, Y., Yamauchi, A., Kawakami, M., Horikawa, M. \& Nakada, T. (1978b) Acute allograft rejection and lymphocyte function in canine lung transplantation. Sci. Rep. Res. Inst. Tohoku Univ.-C., 25, 10-19.

8) Fujimura, S., Kondo, T., Yamauchi, A., Handa, M., Okabe, T., Kawakami, M., Nakada, T. \& Horikawa, M. (1979) Lung transplantation and lymphocyte function in dogs. IV. Lymphocyte function in immunosuppressed animals. Jap. J. Transpl., 14, 277282.

9) Kahan, B.D., Floyd, M., Oka, T., Van Buren, C.T. \& Kerman, R.H. (1979) Immunological techniques in clinical renal transplantation. II. Immunological monitoring post-allografting. Jap. J. Transpl., 14, 14-25.

10) Kondo, T., Fujimura, S., Handa, M., Yamauchi, A., Okabe, T. \& Nakada, T. (1980) Experimental studies on lung preservation. Results of continuous lung perfusion with electrolyte solution. Jap. J. Transpl., 15, 148-152.

11) Kovithavongs, T., Schlaut, J., Pazderka, V., Lao, V., Pazderka, F., Bettcher, K.B. \& Dossetor, J.B. (1978) Posttransplant immunologic monitoring with special consideration of technique and interpretation of LMC. In: Immunologic Monitoring of the Transplant Patient. 1st ed., edited by C.R. Stiller, J.B. Dossetor, N.R.StC. Sinclair, F.T. Rapaport, Grun \& Stratton, Inc., New York, pp. 233-237.

12) Reitz, B.A., Gaudiani, V.A., Hunt, S.A., Wallwork, J., Billingham, M.E., Oyer, P.E., Baumgartner, W.A., Jamieson, S.W., Stinson, E.B. \& Shumway, N.E. (1983) Diagnosis and treatment of allograft rejection in heart-lung transplant recipients. $J$. thorac. cardiovasc. Surg., 85, 354-361.

13) Stiller, C.R., Sinclair, N.R.StC., McGirr, D., Jevnikar, A. \& Ulan, R.A. (1978) Diagnostic and prognostic value of donor-specific posttransplant immune responses: Clinical correlates and in vitro variables. In: Immunologic Monitoring of the Transplant Patient. $\quad$ 1st ed., edited by C.R. Stiller, J.B. Dossetor, N.R.StC. Sinclair \& 
F.T. Rapaport, Grun \& Stratton, Inc., New York, pp. 211-216.

14) Suzuki, C., Nakada, T., Watanabe, A., Fujimura, S. \& Kawakami, M. (1968) Experimental studies of canine lung allotransplantation. The effect of cytotoxic agents and donor spleen cells for immunosuppressive treatment. J. thorac. cardiovasc. Surg., $\mathbf{5 5}$, $200-210$.

15) Veith, F.J. (1978) Lung transplantation. Surg. Clin. North Amer., 58, 357-364.

16) Veith, F.J., Koener, S.K., Siegelman, S.S., Kawakami, M., Kaufman, S., Affai, L.A., Hagstrom, J.W.C. \& Gliedman, M.L. (1973) Diagnosis and reversal of rejection in experimental and clinical lung allografts. Ann. thorac. Surg., 16, 172-183.

17) Veith, F.J., Norin, A.J., Montefusco, C.M., Pinsker, K.L., Kamholz, S.L., Gliedman, M.L. \& Emeson, E. (1981) Cyclosporin A in experinental lung transplantation. Transplantation, 32, 474-481. 